\title{
Research Paper: Selected Kinematic Characteristics Analysis of Knee and Ankle Joints During Block Jump Among Elite Junior Volleyball Players
}

Ali Fatahi ${ }^{1 *}$ (D), Heydar Sadeghi², Razieh Yousefian Molla ${ }^{1}$, Mitra Ameli ${ }^{3}$

1. Department of Sport Biomechanics, Faculty of Physical Education and Sport Sciences, Central Tehran Branch, Islamic Azad University, Tehran, Iran. 2. Department of Sport Biomechanics, Kharazmi University, Tehran, Iran.

3. Department of Physical Education and Sport Sciences, Payam-e-Noor University, Tehran, Iran.

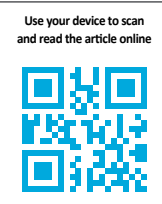

Citation Fatahi A, Sadeghi H, Yousefian Molla R, Ameli M. Selected Kinematic Characteristics Analysis of Knee and Ankle Joints During Block Jump Among Elite Junior Volleyball Players. Physical Treatments. 2019; 9(3):161-168. http://dx.doi. org/10.32598/ptj.9.3.161

: http://dx.doi.org/10.32598/ptj.9.3.161

Keywords:

Biomechanics, Block jump, Volleyball, Knee, Ankle

\section{A B S T R A C T}

Purpose: The present study examined selected kinematic characteristics analysis of knee and ankle joints during block jump in elite junior volleyball players.

Methods: Thirty male junior elite volleyball players (Mean \pm SD age: $18.14 \pm 1.12 \mathrm{y}$, height: $197.10 \pm 3.16 \mathrm{~cm}$, sports history: $4.39 \pm 0.95 \mathrm{y}, \&$ weight: $771.20 \pm 59.83 \mathrm{~N}$ ) participated in this study. A time-synchronized 5-camera sampling at $100 \mathrm{~Hz}$ was used to determine the Three Dimensional (3D) coordinates of markers. Kolmogorov-Smirnov test, linear regression, and magnitude of coefficient were used in SPSS to analyze the obtained data $(\mathrm{P}<0.05)$.

Results: The Mean \pm SD height of block jump was $45.5 \pm 2.06 \mathrm{~cm}$, and the Mean $\pm \mathrm{SD}$ angles of knee and ankle flexion were $93.37 \pm 4.75$ and $21.25 \pm 2.98 \mathrm{~cm}$, respectively. Moreover, there was a negative relationship between knee and ankle flexion angle and block jump height $(-0.051$, -0.054 , respectively) $(\mathrm{P}<0.05)$. However, smaller knee flexion angles had more negative effect on block jump height $(0.741)(\mathrm{P}<0.05)$.

Conclusion: The study results could be used by coaches as a simple tool in jumping performance among junior volleyball players. The obtained data could also be beneficial in the efficient control of applied training procedures.

\footnotetext{
* Corresponding Author:

Ali Fatahi, PhD.

Address: Department of Sport Biomechanics, Faculty of Physical Education and Sport Sciences, Central Tehran Branch, Islamic Azad University, Tehran, Iran. Phone: +98 (912) 5607581

E-mail:fattahiali81@gmail.com
} 


\section{Highlights}

- Kinematic Analysis of Knee and Ankle in Volleyball Block Jump.

\section{Plain Language Summary}

According to the Global interest in Volleyball and great tendency for improving, among volleyball players. enormous scientific investigation is performing. through various methods biochemical analysis of skills is of the great interests. Block Jump is one of the most important skills that it is recommended to concentration on it.

\section{Introduction}

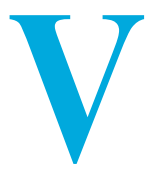

olleyball is the second most participated sport in the world in terms of global participation rates [1]. Pass, set, attack, block, and spike are examples of individual fundamental skills, including a high frequency of various jumping and other kinds of take-off skills creating success in this game $[2,3]$. All of these skills involve various motor skills and abilities, like jumps [1]; elite players are requested to possess a high level of the mentioned skills [4]. Among them, jumping ability highly influences performance in some of the important volleyballs basic skills and is considered as the major performance criterion in volleyball $[2,5]$. Jumps are commonly used during the block, spike, and service actions $[1,5]$. Studies reported a significant correlation between block jump ability and the success rate of spike and block in volleyball games $[1,6]$. Countermovement jump and squat jump are valid tests for volleyball specific block skill. Moreover, research studies based on block jumps are applicable for block optimization in volleyball [7]. A well-executed block jump is defined as reaching to higher height above the net $[1,8]$. Block jump begins with a preliminary downward movement by flexing at the knees and hips (eccentric phase). Then, the knees and hips are immediately extended again to jump vertically (concentric phase) while the hands move upward and are totally extended above the head [9]. It is well accepted to have minimum stop between the eccentric and concentric phases to take advantage of the energy stored by the elastic elements of the muscles [10].

Leg muscle power is determinant for higher jumping; however, many other factors, such as the variety of training modalities (e.g., weight training) [11], plyometric [12], electro-stimulation training [13], jumping techniques, and joint mobility could improve block skills through jumping performance [14-16].
Appropriate jumping technique is a vital element for performance optimization and injury prevention [17]. The mechanisms of many non-contact injuries, like jumping are unclear and represent a multifunctional problem [18]. Thus, magnitude jump movements in volleyball, susceptible players to a broad range of damages, including acute ankle and knee injuries and the overuse conditions of lower extremities [19-21].

Relationships between kinetics and kinematics parameters of jumping were previously assessed. It was proposed that higher forces could be applied to the knee with higher knee extension during block jumping and landing, that may cause numerous problems [22]. For example, Hewett et al. documented a decreased change in the knee flexion angle during the deceleration of the landing phase in block jumping. That is reported to increase frontal plane knee motion and moments, causing a peak Anterior Cruciate Ligament (ACL) strain, especially at the first peak of block Vertical Ground Reaction Force (VGRF) component during the foot/ground contact in landing [23].

Many studies have focused on the kinetics of jumping with respect to injury prevention [17]. However, less attention has been paid to the kinematics of jumping with regard to skill optimization. The biomechanical analysis of block jump revealed that kinematics variables served as components for $35 \%$ of performance optimization [24]. Maximum knee and hip flexion angles would be greater during double-leg tasks, compared with singleleg task in athletes [25]. In addition, an angle of around $90^{\circ}$ would normally produce a higher peak height $[14$, 26]. Countermovement depth could often be neglected in training and testing procedures. Based on maximum block jumps, its optimizations, injury prevention view and as well as in the analyses of jumping techniques [27]. Furthermore, in terms of the relationship between kinematic analysis of jumping and injuries, many players with different conditions and genders demonstrated 
decreased knee flexion or increased knee abduction at the time of injury [27-29].

We investigated the effect of knee and ankle joints kinematics on block jumps as a specific task in volleyball which remained neglected in the literature. Therefore, this study performed the kinematic analysis of knee and ankle joints during block jump in elite junior volleyball players.

\section{Materials and Methods}

Thirty healthy male volleyball players of the junior national team (Mean \pm SD age: $18.14 \pm 1.12 \mathrm{y}$, height: $197.10 \pm 3.16 \mathrm{~cm}$, sports history: $4.39 \pm 0.95 \mathrm{y}$, \& weight: $771.20 \pm 59.83 \mathrm{~N}$ ) participated in this study. The test procedure was described to all study participants, and they provided signed consent forms. All players participated in scheduled 2-hour volleyball training sessions three times a week for the past 4 months. To be included in the test, musculoskeletal and lower extremity injury assessments were performed by an expert physician using the Persian version of Standard Australian Injury questionnaire. Those who were at risk of leg discrepancy, ACL rupture, bone fracture, patellar dislocation, and meniscus tear or had history of any lower extremities' injuries were excluded from the experiment. The testing procedure was designed according to Helsinki Deceleration (1975) and approved by the Ethics Committee of Kharazmi University.

This descriptive study was conducted at the Biomechanics Laboratory of National Olympic Committee of Iran. Testing performance time was set at the ordinary

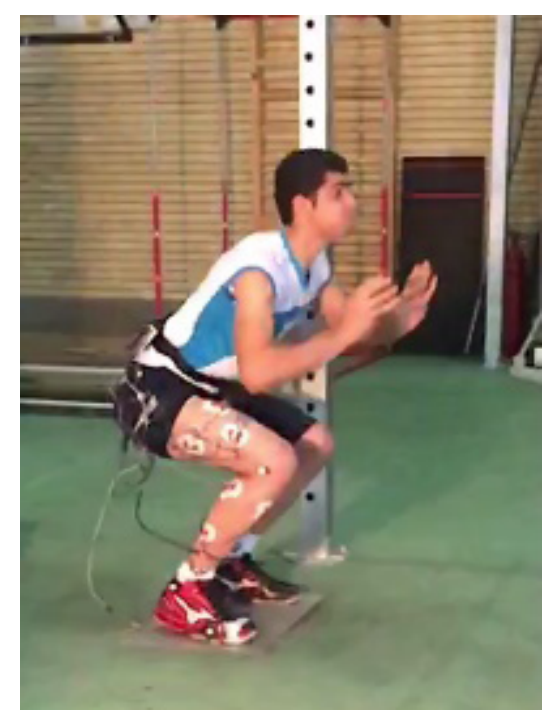

Figure 1. Block jump technique

A. Peak Flexion of Block Jump; B. Final Phase of Block Jump time of daily activities. The study participants were requested to warm up for 15 minutes, same as the official condition of the game. Block jump (Figure 1) was the considered test, and each participant performed threeblock jumps, and the best jump was considered for further analysis. No verbal instruction was allowed to decrease learning effect caused by coach.

A time-synchronized 5-camera Vicon 512 system (Vicon, Oxford, England) sampling at $100 \mathrm{~Hz}$ was used to determine the Three Dimensional (3D) coordinates of 7 reflective markers (25 $\mathrm{mm}$ diameter). Markers were directly placed on the skin over anatomical landmarks by the Helen Hayes system's lower body marker set (hip, knee, ankle) of the dominant leg [30]. The obtained data were recorded in an Excel file. Knee and ankle angles in sagittal plane (flexion/extension) were determined according to absolute values mentioned by Winter [30] (Figure 1). All statistical analyses were performed using SPSS. Kolmogorov-Smirnov test was used to identify data normality. Next, linear regression was used to understand the relationship between knee and ankle joint angles with block jump height as well as the magnitude coefficient of each variable $(\mathrm{P}<0.05)$.

\section{Results}

Table 1 presents the Mean \pm SD values of block jumps and the kinematic variables of junior elite volleyball players. Knee flexion angle was more considerable than ankle dorsiflexion angle. The regression coefficient between joint angles and block jump in volleyball players is listed in Table 2. According to it, knee and ankle joints had a negative relationship with block jump $(-0.341 \&$

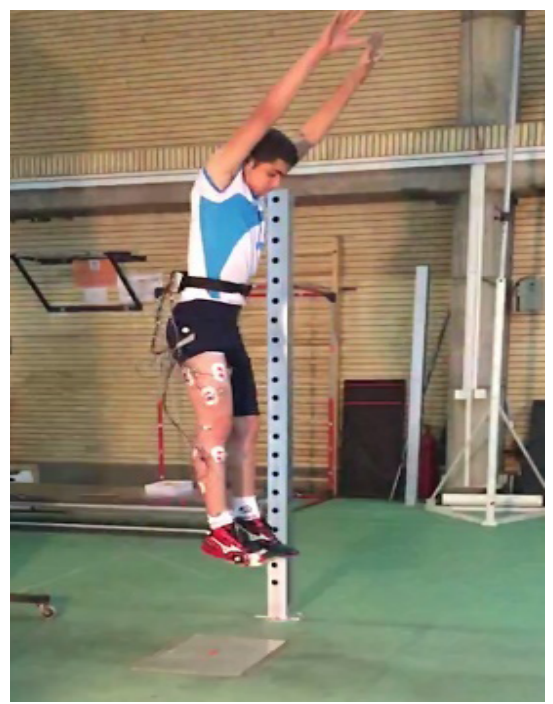

PHYSICAL TREA $\mid$ MENTS 


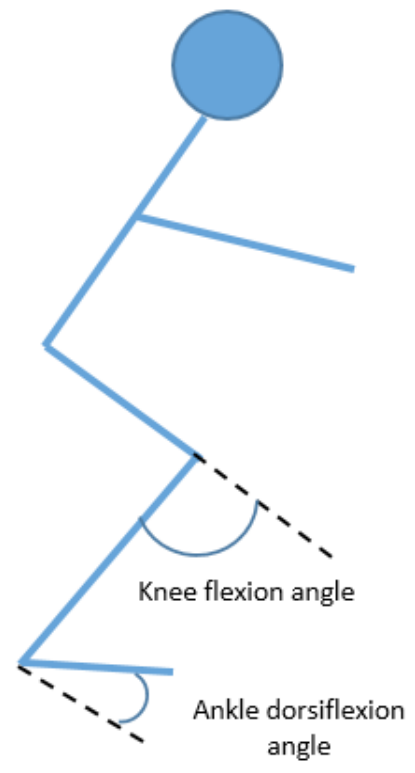

PHYSICAL TREA $\|$ MENTS

Figure 2. Knee and ankle angles assessments in block jump

-0.226 , respectively). Knee flexion had a more significant adverse effect on the block jump performance of elite junior volleyball players.

\section{Discussion}

The achieved results indicated differences and negative relationships between knee and ankle joints during block jumps among junior volleyball players in the sagittal plane. Moreover, the Mean \pm SD value of height in male junior's block jump was equal to $45.5 \pm 2.06 \mathrm{~cm}$, which is higher than some other studies [31-35]. Maybe these contradictions in results are mainly because of the gender, age, and skill level of the participants of other studies. Other studies' samples were female or recreational volleyball players who mostly have weaker muscle strength and power, comparing to male athletes. Projecting the body at the optimum take-off angle is essential for successful block jumping in volleyball. Furthermore, block jump is mainly dependent on leg muscle power and the ability of muscles to generate enough forces
[36]. In addition, considering appropriate technique and suitable joint sequence appearance in jumping performance are as necessary as other parameters.

None of these investigations considered the joints' angle as a contributing factor to the better performance of block jump. Thus, anthropometrical and physiological characteristics are vital in the height and degrees of ankle and knee during block jump.

Kinematic variables are not only considered in jumping but also crucial in landing techniques. Some authors investigated lower extremity kinematics during landing from a jump [25, 28, 37, 38]. Knee and ankle dorsiflexion angle, as the most common kinematics variables of the lower extremity, are essential in injury prevention, especially for ACL rupture. Biomechanically, increased knee valgus, high abduction loads, and small knee flexion angles lead to an increased risk of ACL injury during landing from a jump [22, 37]. Furthermore, due to the effect of knee flexion on the patella-tendon-tibia shaft angle, a given load acting through the patellar ligament might place a greater strain on the ACL if the knee flexion angle is small [22]. Besides the great risk of ACL injury, patellofemoral pain is significantly associated with reduced peak knee flexion and increased loading rates [39]. Ankle angle is also a determinant for jumping - landing-related injuries, like patellar tendinopathy. Smaller ankle dorsiflexion angle during jumping makes the players more susceptible to patellar tendinopathy [40].

The obtained regression coefficient results indicated that knee and ankle joints negatively affect block jump (-0.341 \& -0.226 , respectively). Furthermore, differences between ankle and knee joint flexion angles were not significant $(\mathrm{P}<0.05)$. These findings disagree with those of Satoru et al. who stated a relationship between jumping performance and knee flexion angle; knee flexion also had a controlling role in jumping performance [38]. Block jumping is a multi-joint movement with tow-joint muscles and requires the intra- and inter-muscular coordination (i.e., the ability of agonists, antagonists, and synergists to cooperate in performing the task). This

Table 1. Mean $\pm S D$ variables of block jumps and the kinematics of junior elite volleyball players $(n=30)$

\begin{tabular}{cccc}
\hline & Min & Max & 48.43 \\
\hline Block height $(\mathrm{cm})$ & 42.39 & $97.5 \pm 2.06$ & $93.37 \pm 4.75$ \\
The peak of the knee flexion angle (deg.) & 89.45 & 24.53 & $21.25 \pm 2.98$ \\
\hline The peak of ankle dorsiflexion angle (deg.) & 18.45 & 24.25 & \\
\hline
\end{tabular}


Table 2. Regression coefficient between knee and ankle angles and block jump

\begin{tabular}{|c|c|c|c|c|c|}
\hline & \multicolumn{2}{|c|}{ Unstandardized Coefficients } & \multirow{2}{*}{$\begin{array}{c}\text { Standardized Coefficients } \\
\text { Beta }\end{array}$} & \multirow{2}{*}{$\mathbf{t}$} & \multirow{2}{*}{ Sig. $(P<0.05$} \\
\hline & B & Std. Error & & & \\
\hline Constant & 51.376 & 13.448 & & 3.820 & .004 \\
\hline Knee angle (deg.) & -0.051 & 0.149 & -0.117 & -0.341 & 0.741 \\
\hline Ankle Angle (deg.) & -0.054 & 0.237 & -0.077 & -0.226 & 0.826 \\
\hline
\end{tabular}

Block jump $(\mathrm{cm})=51.376$ - 0.051×knee flexion angle (deg.) - 0.054×Ankle dorsiflexion angle (deg.)

technique requires moderate eccentric muscle activation, followed by high concentric muscle activation.

Additionally, it is a complex task requiring the quick and harmonized coordination of jumper's body segments, first for the push-off, then for the flight, and lastly for the landing phase [41]. In jumping, angles in knee and ankle flexion, as two main factors derived from our investigation, can be introduced through the activation of the bi-articular gastrocnemius muscle before the end of the push-off. Such process enables the transportation of the power generated by the knee extensors from the knee to the ankle joint. Thus, by gastrocnemius muscle activation, a rapid extension of the foot is produced. This extension has a more significant effect on the block velocity than the extension of the almost straightened knee. Moreover, the elastic connection of gastrocnemius muscle to foot plays a vital role in enhancing the effectiveness and efficiency of human performance. Appropriate sequence and magnitude of knee and ankle dorsiflexion could lead to optimized produced energy from muscles to elastic tendons and from one segment to the other [5].

Block jump performance among the most essential skills in volleyball. Besides the ability of the muscle in force production and output power, kinematic variables, such as knee and ankle angles should be considered for block jump optimization. A high or low value of knee and ankle flexion could lead to energy dissipation and inappropriate energy transfer, especially in gastrocnemius muscle; as bi-articular muscle acting on knee and ankle. Biomechanics constraints for block jump empower the hypothesized model which contributes to building lower articulated body models with high possibility identical with the real human lower body. Further investigations are necessary to find out more determinants affecting jumping performance in volleyball players.

The study results could be used by coaches as a simple tool to improve jumping performance among junior volleyball players. The obtained data could also be beneficial in the efficient control of applied training procedures.

\section{Ethical Considerations}

\section{Compliance with ethical guidelines}

All athletes read and signed a written informed consent before testing and completed a detailed injury history form. The study participants were informed about the purpose of research and its implementation stages; they were also assured about the confidentiality of their information. Moreover, they were allowed to discontinue participation in the study as desired. Finally, if desired, the results of the research would be available to them.

\section{Funding}

This research received no specific grant from funding agencies in the public, commercial, or not-for-profit sectors.

\section{Authors' contributions}

All authors contributed in designing, running, and writing all parts of the research.

\section{Conflict of interest}

The authors declared no conflict of interest.

\section{Acknowledgments}

The authors appreciate all of Iran Volleyball Federation staff for their cooperation in this study.

\section{References}

[1] Abendroth-Smith J, Kras J. More B-BOAT: The volleyball spike: Bump set spike!. Journal of Physical Education, Recreation \& Dance. 1999; 70(3):56-9. [DOI:10.1080/07303084.1 999.10605897]

[2] Abidin NZ, Adam MB. Prediction of vertical jump height from anthropometric factors in male and female martial arts 
athletes. The Malaysian Journal of Medical Sciences. 2013; 20(1):39-45. [PMID] [PMCID]

[3] Agel J, Palmieri-Smith R, Dick R, Wojtys E, Marshall S. Descriptive epidemiology of collegiate women's volleyball injuries: National Collegiate Athletic Association Injury Surveillance System, 1988-1989 Through 2003-2004. Journal of Athletic Training. 2007; 42(2), 395. [PMID] [PMCID]

[4] Buśko K, Michalski R, Mazur J, Gajewski J. Jumping abilities in elite female volleyball players: Comparative analysis among age categories. Biology of Sport. 2012; 29(1), 317-9. [DOI:10.5604/20831862.1022654]

[5] Chang HY, Hsu WS, Chiang JY, Liu SY, Ho HC. Gender difference in knee motion pattern during vertical jump. ISBSConference Proceedings Archive. 2008; 1(1):1-8.

[6] Davis D, Briscoe D, Markowski C, Saville S, Taylor C. Physical characteristics that predict vertical jump performance in recreational male athletes. Physical therapy in Sport. 2003; 4(4):167-74. [DOI:10.1016/S1466-853X(03)00037-3]

[7] de Oliveira Silva D, Briani RV, Pazzinatto MF, Ferrari D, Aragão FA, de Azevedo FM. Reduced knee flexion is a possible cause of increased loading rates in individuals with patellofemoral pain. Clinical Biomechanics. 2015; 30(9):971-5. [DOI:10.1016/j.clinbiomech.2015.06.021] [PMID]

[8] Donohue MR, Ellis SM, Heinbaugh EM, Stephenson ML, Zhu Q, Dai B. Differences and correlations in knee and hip mechanics during single-leg landing, single-leg squat, double-leg landing, and double-leg squat tasks. Research in Sports Medicine. 2015; 23(4):394-411. [DOI:10.1080/1543862 7.2015.1076413] [PMID]

[9] Eom HJ, Schutz RW. Statistical analyses of volleyball team performance. Research Quarterly for Exercise and Sport. 1992; 63(1):11-8. [DOI:10.1080/02701367.1992.10607551] [PMID]

[10] Fattahi A, Ameli M, Sadeghi H, Mahmoodi B. Relationship between anthropometric parameters with vertical jump in male elite volleyball players due to game's position. Journal of Human Sport and Exercise. 2012; 7(3):714-26. [DOI:10.4100/jhse.2012.73.11]

[11] Fleck SJ, Case S, Puhl J, Van PH. Physical and physiological characteristics of elite women volleyball players. Canadian journal of applied sport sciences. Journal Canadien des Sciences Appliquees au Sport. 1985; 10(3):122-6. [PMID]

[12] Hewett TE, Myer GD, Ford KR, Heidt Jr RS, Colosimo AJ, McLean SG, et al. Biomechanical measures of neuromuscular control and valgus loading of the knee predict anterior cruciate ligament injury risk in female athletes: a prospective study. The American Journal of Sports Medicine. 2005; 33(4):492-501. [DOI:10.1177/0363546504269591] [PMID]

[13] Holden S, Boreham C, Doherty C, Wang D, Delahunt E. Clinical assessment of countermovement jump landing kinematics in early adolescence: sex differences and normative values. Clinical Biomechanics. 2015; 30(5):469-74. [DOI:10.1016/j.clinbiomech.2015.03.008] [PMID]

[14] Hughes G, Watkins J, Owen N. The effects of opposition and gender on knee kinematics and ground reaction force during landing from volleyball block jumps. Research Quarterly for Exercise and Sport. 2010; 81(4):384-91. [DOI:10.1080 /02701367.2010.10599698] [PMID]
[15] Kai S, Nakahara M, Watari K, Murakami S, Yoshimoto R Knee joint angle at the time of adjustment to submaximal jumping in healthy men. Journal of Physical Therapy Science. 2006; 18(1):11-3. [DOI:10.1589/jpts.18.11]

[16] Koga H, Nakamae A, Shima Y, Iwasa J, Myklebust G, Engebretsen L, et al. Mechanisms for noncontact anterior cruciate ligament injuries: Knee joint kinematics in 10 injury situations from female team handball and basketball. The American Journal of Sports Medicine. 2010; 38(11):2218-25. [DOI:10.1177/0363546510373570] [PMID]

[17] Lehnert $M$, Sigmund $M$, Lipinska $P$, Vařeková R, Hroch $\mathrm{M}$, Xaverová $\mathrm{Z}$, et al. Training-induced changes in physical performance can be achieved without body mass reduction after eight week of strength and injury prevention oriented programme in volleyball female players. Biology of Sport. 2017; 34(2):205-15. [DOI:10.5114/biolsport.2017.65995] [PMID] [PMCID]

[18] Leporace G, Praxedes J, Pereira GR, Pinto SM, Chagas D, Metsavaht $\mathrm{L}$, et al. Influence of a preventive training program on lower limb kinematics and vertical jump height of male volleyball athletes. Physical Therapy in Sport. 2013; 14(1):35-43. [DOI:10.1016/j.ptsp.2012.02.005] [PMID]

[19] Malatesta D, Cattaneo F, Dugnani S, Maffiuletti NA Effects of electromyostimulation training and volleyball practice on jumping ability. The Journal of Strength \& Conditioning Research. 2003; 17(3):573-9. [DOI:10.1519/00124278-200308000-00025]

[20] Mandic R, Jakovljevic S, Jaric S. Effects of countermovement depth on kinematic and kinetic patterns of maximum vertical jumps. Journal of Electromyography and Kinesiology. 2015; 25(2):265-72. [DOI:10.1016/j.jelekin.2014.11.001] [PMID] [PMCID]

[21] Markovic G. Does plyometric training improve vertical jump height? A meta-analytical review. British Journal of Sports Medicine. 2007; 41(6):349-55. [DOI:10.1136/ bjsm.2007.035113] [PMID] [PMCID]

[22] Moran KA, Wallace ES. Eccentric loading and range of knee joint motion effects on performance enhancement in vertical jumping. Human Movement Science. 2007; 26(6):824-40. [DOI:10.1016/j.humov.2007.05.001] [PMID]

[23] Moura T, Porto A, Gabriel L, de Oliveira R, Okazaki V. Vertical jump height prediction through the analysis of ground reaction forces. ISBS-conference proceedings archive. 29 June- 3 July 2015; Poitiers, France.

[24] Nikolaidis PT, Gkoudas K, Afonso J, Clemente-Suarez VJ, Knechtle B, Kasabalis S, et al. Who jumps the highest? Anthropometric and physiological correlations of vertical jump in youth elite female volleyball players. The Journal of Sports Medicine and Physical Fitness. 2017; 57(6):802-10. [DOI:10.23736/S0022-4707.16.06298-8] [PMID]

[25] Papageorgiou A, Spitzley W. Handbook for competitive volleyball. Aachen: Meyer \& Meyer Verlag; 2003.

[26] Podraza JT, WhiteSC. Effect of knee flexion angle on ground reaction forces, knee moments and muscle co-contraction during an impact-like deceleration landing: Implications for the non-contact mechanism of ACL injury. The Knee. 2010; 17(4):291-5. [DOI:10.1016/j.knee.2010.02.013] [PMID]

[27] Ratamess N. ACSM's foundations of strength training andconditioning. Chine: Lippincott Williams \& Wilkins; 2012. 
[28] Reeser JC, Verhagen EA, Briner WW, Askeland TI, Bahr R. Strategies for the prevention of volleyball related injuries. British Journal of Sports Medicine. 2006; 40(7):594-600. [DOI:10.1136/bjsm.2005.018234] [PMID] [PMCID]

[29] Richards DP, Ajemian SV, Wiley JP, Brunet JA, Zernicke RF. Relation between ankle joint dynamics and patellar tendinopathy in elite volleyball players. Clinical Journal of Sport Medicine. 2002; 12(5):266-72. [DOI:10.1097/00042752200209000-00002] [PMID]

[30] Salles AS, Baltzopoulos V, Rittweger J. Differential effects of countermovement magnitude and volitional effort on vertical jumping. European Journal of Applied Physiology. 2011; 111(3):441-8. [DOI:10.1007/s00421-010-1665-6] [PMID]

[31] Sattler T, Sekulic D, Hadzic V, Uljevic O, Dervisevic E. Vertical jumping tests in volleyball: Reliability, validity, and playing-position specifics. The Journal of Strength \& Conditioning Research. 2012; 26(6):1532-8. [DOI:10.1519/ JSC.0b013e318234e838] [PMID]

[32] Shultz SJ, Schmitz RJ, Benjaminse A, Chaudhari AM, Collins M, Padua DA. ACL research retreat VI: An update on ACL injury risk and prevention: March 22-24, 2012; Greensboro, NC. Journal of Athletic Training. 2012; 47(5):591-603. [DOI:10.4085/1062-6050-47.5.13] [PMID] [PMCID]

[33] Spence DW, Disch JG, Fred HL, Coleman AE. Descriptive profiles of highly skilled women volleyball players. Medicine and Science in Sports and Exercise. 1980; 12(4):299-302. [DOI:10.1249/00005768-198024000-00013] [PMID]

[34] Tillman MD, Hass CJ, Brunt D, Bennett GR. Jumping and landing techniques in elite women's volleyball. Journal of Sports Science \& Medicine. 2004; 3(1):30-6. [PMID] [PMCID]

[35] Vanezis A, Lees A. A biomechanical analysis of good and poor performers of the vertical jump. Ergonomics. 2005; 48(11-14):1594-603. [ [DOI:10.1080/00140130500101262] [PMID]

[36] Wagner H, Tilp M, Von Duvillard SP, Müller E. Kinematic analysis of volleyball spike jump. International Journal of Sports Medicine. 2009; 30(10):760-5. [DOI:10.1055/s-0029-1224177] [PMID]

[37] West T, Ng L, Campbell A. The effect of ankle bracing on knee kinetics and kinematics during volleyball-specific tasks. Scandinavian Journal of Medicine \& Science in Ssports. 2014; 24(6):958-63. [DOI:10.1111/sms.12130] [PMID]

[38] Wilson GJ, Murphy AJ, Giorgi A. Weight and plyometric training: effects on eccentric and concentric force production. Canadian Journal of Applied Physiology. 1996; 21(4):301-15. [DOI:10.1139/h96-026] [PMID]

[39] Winter D. Biomechanics and motor control of human movement. Hoboken: John Wiley \& Sons; 2009. [DOI:10.1002/9780470549148]

[40] Zahálka F, Malý T, Malá L, Ejem M, Zawartka M. Kinematic analysis of volleyball attack in the net center with various types of take-off. Journal of Human Kinetics. 2017; 58(1):26171. [DOI:10.1515/hukin-2017-0115] [PMID] [PMCID]

[41] Zahradnik D, Jandacka D, Farana R, Uchytil J, Hamill J. Identification of types of landings after blocking in volleyball associated with risk of ACL injury. European Journal of Sport Science. 2017; 17(2):241-8. [DOI:10.1080/17461391.201 6.1220626] [PMID] 
This Page Intentionally Left Blank 